\title{
Assessment of questionnaire-based PCB exposure focused on food frequency in birth cohorts in Japan
}

\author{
Akifumi Eguchi $^{1} \cdot$ Masae Otake $^{1} \cdot$ Masamichi Hanazato $^{1} \cdot$ Norimichi Suzuki $^{1}$. \\ Yoshiharu Matsuno $^{1} \cdot$ Hiroko Nakaoka $^{1} \cdot$ Emiko Todaka $^{1} \cdot$ Chisato Mori $^{1,2}$
}

Received: 20 May 2016 / Accepted: 14 November 2016/Published online: 22 November 2016

(C) The Author(s) 2016. This article is published with open access at Springerlink.com

\begin{abstract}
We investigated the relationship between food frequency questionnaire (FFQ) responses and serum polychlorinated biphenyl (PCB) levels of mothers and fathers recruited from the Chiba Regional Center, which is one of the 15 regional centers of the Japan Environment and Children's Study (mothers: $n=1477$, fathers: $n=219$ ). The expected PCB values were estimated from the participants' FFQ answers and medical records (age, body mass index and number of deliveries). Based on the stepwise forward selection results of Bayesian regression models, age and fish and egg consumption were positively associated with PCB concentrations and a number of deliveries were negatively associated with PCB concentrations in mothers, whereas only age was positively associated with PCB concentrations in fathers.

These findings indicated that the estimation of daily dietary intake may be useful for the prediction of PCB concentration for mothers.
\end{abstract}

Keywords PCBs $\cdot$ Human serum $\cdot$ Food frequency $\cdot$ Diet

\section{Introduction}

The health effects of fetal and child environmental exposure to chemicals are a major concern, and several cohort studies have

Responsible editor: Philippe Garrigues

Chisato Mori

cmori@faculty.chiba-u.jp

1 Center for Preventive Medical Sciences, Chiba University, Inage-ku Yayoi-cho 1-33, Chiba City, Japan

2 Department of Bioenvironmental Medicine, Graduate School of Medicine, Chiba University, Chuo-ku Inohana 1-8-1, Chiba City, Japan been conducted worldwide (Ayotte et al. 2003; Govarts et al. 2012; James et al. 2002). Polychlorinated biphenyls (PCBs) are known to affect the endocrine systems in humans. Despite being banned in 2001 by the Stockholm Convention (UNEP 2001), PCBs widely persist in wildlife and humans because of their lipophilic properties, low water solubility, and bioaccumulation in fatty tissues (Safe 1994). PCBs are reported to have numerous adverse human health effects, including reproductive (Leoni et al. 1989), developmental (Jorissen 2007), immunological (Glynn et al. 2008), and neurological (Prince et al. 2006). Food is a major source of exposure to PCBs and dioxins, which are related compounds (Caspersen et al. 2013; Kvalem et al. 2009). It has been reported that the consumption of fish was positively associated with serum levels of total PCBs among Japanese women (Tsukino et al. 2006), suggesting that human PCB contamination levels are strongly affected by eating habits.

Self-administered, semi-quantitative food frequency questionnaire (FFQ) has been used to assess the nutrient and food intake of subjects in large-scale epidemiologic studies from several countries, including Japan (Sasaki et al. 2003; Tsugane et al. 2003a; Willett 1994). If groups at high risk for PCB contamination could be identified by an FFQ approach, without chemical analyses, significant cost and time could be saved. Various prediction models for PCB concentrations in humans have been generated using dietary intake (Kvalem et al. 2009; Laden et al. 1999; Xue et al. 2014); however, few studies have addressed this issue in Japanese populations.

The Japan Environment and Children's Study (JECS) is a nationwide birth cohort study of 100,000 parent-child pairs that evaluates the impact of various environmental factors on children's health and development (Kawamoto et al. 2014). Here, in an adjunct study of JECS, we evaluated the relationship between FFQ responses and serum PCB contamination levels of participants at the Chiba Regional Center. 


\section{Materials and methods}

This study was approved by the Ethics Committee of Chiba University, Japan. Data of participants (age, body mass index [BMI], and a number of deliveries) and FFQ were completed by mothers $(n=1716)$ and fathers $(n=318)$ recruited from the Chiba Regional Center, which is one of the 15 regional centers of JECS. Age, BMI, and reproductive information were collected from medical record information. Participants who had completed $<60 \%$ of the FFQ, outlier of energy intake (below $600 \mathrm{kcal} /$ day or above $4000 \mathrm{kcal} /$ day), and not completed the medical record information (age, BMI, and reproductive information) were excluded from the analysis. Finally, the remaining 1477 mothers $(86.1 \%)$ and 219 fathers $(68.9 \%)$ were used for all analysis (Table 1).

The FFQ used in the JECS is a validated, self-administered diet questionnaire that has been evaluated in previous studies with respect to nutrient factors (Ishihara et al. 2003; Iso et al. 2003; Tsubono et al. 2003; Tsugane et al. 2003b). The FFQ was a self-administered questionnaire comprising 13 pages. The FFQ included food lists (cereals, eggs, fat and oils, fish and shellfish, fruits, meats, mushrooms, milks, potatoes and starches, and vegetables), standard units (volumes; 0.5 for small, 1.0 for medium, and 1.5 for large), portion sizes (e.g., $30 \mathrm{~g}$ portion $^{-1}$ ), and frequencies (ranging from less than once per month to more than seven times per day). Moreover, eating habits (e.g., frequency of having breakfast, eating out, and speed of eating) were assessed by the questionnaire. The subjects reported their intake frequency and portions of consumption for the past year (Sakurai et al. 2004; Takasuga et al. 2004). Consumption amounts were calculated using the frequencies, standard units, and portion sizes for the various food items of the FFQ. This amount was then energy adjusted using the energy density method (Drewnowski and Specter 2004).

During the mother's pregnancy, blood samples of $30 \mathrm{~mL}$ were drawn once from both mothers and fathers. PCB levels were analyzed according to the procedures previously reported (Jotaki et al. 2011; Mori et al. 2014). Approximately $1 \mathrm{~g}$ of serum was hydrolyzed with $1 \mathrm{M}$ potassium hydroxide that was diluted in ethanol for $18 \mathrm{~h}$ and extracted three times with hexane. The extract was washed three times with distilled water and then dehydrated with anhydrous sodium sulfate. The solution was concentrated by evaporation to approximately $2 \mathrm{~mL}$, eluted through a Florisil column (Florisil PR; GL Sciences, Tokyo, Japan) with $50 \mathrm{~mL}$ hexane, evaporated to a final volume of $1 \mathrm{~mL}$, and analyzed by packed-column gas chromatography with an electron capture detector (GC/ECD; GC-17A, Shimadzu, Kyoto, Japan). The PCB concentration was calculated as the sum of the major eight peaks shown after $p, p^{\prime}$-DDE on the chromatogram, based on the peaks detected in a Kanechlor mixture standard (Kanechlor 300, 400, 500, and $600=1: 1: 1: 1)($ JIS K 0093: 2006; Mori et al. 2014). The

Table 1 Subjects' characteristics, FFQ data in fathers and mothers recruited in Chiba Regional Center of JECS

\begin{tabular}{|c|c|c|c|c|c|c|c|c|c|c|c|c|c|c|}
\hline & \multicolumn{7}{|c|}{ Mothers $(n=1477)$} & \multicolumn{7}{|c|}{ Fathers $(n=219)$} \\
\hline & Mean & $\begin{array}{l}\text { Standard } \\
\text { deviation }\end{array}$ & $0 \%$ & $25 \%$ & $50 \%$ & $75 \%$ & $100 \%$ & Mean & $\begin{array}{l}\text { Standard } \\
\text { deviation }\end{array}$ & $0 \%$ & $25 \%$ & $50 \%$ & $75 \%$ & $100 \%$ \\
\hline Age & 31.0 & 5.0 & 17.0 & 28.0 & 31.0 & 35.0 & 46.0 & 32.9 & 6.0 & 20.0 & 29.0 & 32.0 & 37.0 & 64.0 \\
\hline BMI & 21.4 & 3.2 & 14.6 & 19.2 & 20.7 & 22.7 & 39.9 & 24.4 & 3.9 & 16.9 & 21.9 & 23.8 & 26.2 & 39.0 \\
\hline Height & 158.2 & 5.4 & 140.0 & 155.0 & 158.0 & 162.0 & 178.0 & 171.4 & 5.7 & 158.0 & 167.3 & 171.5 & 175.0 & 190.0 \\
\hline Weight & 53.5 & 8.9 & 37.0 & 48.0 & 52.0 & 57.0 & 106.0 & 71.8 & 12.3 & 47.3 & 63.0 & 70.0 & 78.7 & 110.0 \\
\hline $\begin{array}{c}\text { A number of } \\
\text { deliveries }\end{array}$ & 0.9 & 0.8 & 0.0 & 0.0 & 1.0 & 1.0 & 5.0 & & & & & & & \\
\hline Energy (kcal) & 1845 & 583 & 685 & 1426 & 1758 & 2153 & 3973 & 2208 & 625 & 1056 & 1756 & 2158 & 2593 & 3920 \\
\hline \multicolumn{15}{|c|}{ Intakes of foods (g/day/kcal) } \\
\hline Eggs & 15.4 & 13.1 & 0.0 & 7.6 & 13.3 & 19.6 & 194.3 & 15.7 & 20.4 & 0.0 & 5.8 & 10.7 & 18.3 & 145.9 \\
\hline Fats and oils & 6.0 & 2.4 & 1.2 & 4.3 & 5.6 & 7.2 & 26.3 & 5.4 & 3.9 & 0.0 & 3.0 & 4.5 & 6.9 & 36.5 \\
\hline $\begin{array}{l}\text { Fish and } \\
\text { shellfish }\end{array}$ & 22.1 & 15.0 & 0.0 & 12.4 & 20.0 & 28.8 & 154.8 & 22.0 & 18.5 & 0.0 & 8.0 & 17.6 & 30.8 & 119.8 \\
\hline Fruits & 89.1 & 70.5 & 0.0 & 39.6 & 74.8 & 121.7 & 740.2 & 53.2 & 71.4 & 0.0 & 10.3 & 33.3 & 72.3 & 548.1 \\
\hline Meats & 38.9 & 19.5 & 0.0 & 25.2 & 36.1 & 49.0 & 143.9 & 48.6 & 36.8 & 0.0 & 23.9 & 39.7 & 60.2 & 241.0 \\
\hline Milks & 138.8 & 126.2 & 0.0 & 59.6 & 108.6 & 171.2 & 914.5 & 94.3 & 163.2 & 0.0 & 16.4 & 45.4 & 96.7 & 1315 \\
\hline $\begin{array}{l}\text { Potatoes and } \\
\text { starches }\end{array}$ & 13.9 & 9.5 & 0.0 & 7.3 & 12.1 & 18.4 & 89.4 & 11.0 & 11.0 & 0.0 & 3.6 & 8.4 & 14.7 & 88.5 \\
\hline Vegetables & 106.0 & 62.7 & 0.0 & 64.1 & 91.4 & 133.8 & 829.0 & 82.1 & 78.5 & 0.0 & 34.4 & 57.2 & 110.4 & 492.9 \\
\hline Water & 217.7 & 313.9 & 0.0 & 22.1 & 97.1 & 286.0 & 2386 & 174.5 & 322.7 & 0.0 & 22.3 & 68.8 & 215.4 & 3585 \\
\hline
\end{tabular}


detection limit was $0.1 \mathrm{ng} \mathrm{g}^{-1}$ wet weight; samples below the lower level of detection were assigned to a value of $0.05 \mathrm{ng} \mathrm{g}^{-1}$ (JIS K 0093: 2006). The total PCB concentrations that were analyzed by packed GC/ECD were strongly correlated $\left(R^{2}>0.996\right)$ with values analyzed by GC-HRMS in our previous study (Mori et al. 2014).

\section{Statistical analysis}

The relationships between body mass index (BMI), age, FFQ, and PCB concentrations (wet weight) were analyzed by the Bayesian linear regression modeling separately by gender for both parents. The PCB concentration data was assessed for normal distribution with the Shapiro-Wilkes test and was not normally or log-normally distributed but was right-skewed and showed slightly heavy tails. Due to the distribution of PCB concentration, Bayesian linear regression modeling was conducted using a No-U-Turn Sampler variant of the Hamiltonian Markov Chain Monte Carlo (Hoffman and Gelman 2014) approach that was implemented in Stan version 2.8.0 and accessed through the rstan packing (Stan Development Team 2015) of the $\mathrm{R}$ program ( $\mathrm{R}$ Core Team 2014). This approach was chosen because Bayesian linear regression modeling is sufficiently tolerant to handle skewed and heavy-tailed distributions. We used the non-informative $N\left(0,100^{2}\right)$ prior distribution as the prior mean PCB concentration in all models.

In the Bayesian linear regression modeling, we ran three chains from random initializations each with 10,000 samples, thinned to every 2 samples, and discarded the first 5000 samples from each as burn-in. We checked convergence by ensuring that R-hat, an estimate of the potential scale reduction of the posterior if sampling were to be infinitely continued, was below 1.1 (Gelman et al. 2014). The reported empirical 95\% credible intervals $(95 \% \mathrm{CI})$ represent the 2.5 th to 97.5 th percentiles of the highest posterior density interval calculated from the posterior samples.
Following this, the predictive accuracy from various models can be compared using the Watanabe-Akaike information criterion (WAIC) (Vehtari and Gelman 2014; Watanabe 2010):

$\mathrm{WAIC}=-2\left(\widehat{\operatorname{lpd}}-\widehat{P}_{\text {waic }}\right)$

where $\widehat{\operatorname{lpd}}$ represents the computed log pointwise predictive density and $P_{\text {waic }}$ is the estimated effective number of parameters (Vehtari and Gelman 2014; Watanabe 2010). The model with the lowest WAIC is selected to achieve a trade-off between model complexities. WAIC was derived based on a singular learning theory as an asymptotically unbiased approximation to the outof-sample prediction error and is a generalization of Akaike's information criterion that is applicable to both regular and singular statistical models (Watanabe 2010). The variable selection in the Bayesian linear regression modeling was evaluated based on the stepwise forward selection method by WAIC.

\section{Results and discussion}

The mean \pm standard deviation (SD) serum concentrations of PCBs in fathers and mothers were $0.38 \pm 0.21$ and $0.28 \pm 0.16 \mathrm{ng} \mathrm{g}^{-1}$ wet weights, respectively (Table 2 ). The mean concentrations of PCBs stratified by a number of deliveries in mothers are shown in Table 2. PCB concentrations in the fathers were higher than in the mothers, and among the mothers, serum PCB concentrations were lower as the number of deliveries was greater. PCB levels in this study are comparable or slightly lower than the serum levels of previous cohort studies in Japan, USA, and European countries (Table 3) (Govarts et al. 2012; Inoue et al. 2006; Patterson et al. 2009). Based on the stepwise forward selection results, consumption of fish and eggs was selected along with age and number of delivery for the model of mothers by WAIC (Tables 4 and 6$)$. In mothers, age $[\beta=0.26,95 \%$ CI $(0.23$, $0.29)]$ and fish $[\beta=0.055,95 \%$ CI $(0.029,0.082)]$ and egg consumptions $[\beta=0.025,95 \%$ CI $(-0.00027,0.052)]$ were
Table 2 PCB concentrations (ng/ $\mathrm{g}$ wet wt.) in serum from fathers and mothers

\begin{tabular}{lcllllll}
\hline & Mean & Standard deviation & Min & $25 \%$ & $50 \%$ & $75 \%$ & Max \\
\hline Father $(n=219)$ & 0.38 & 0.21 & 0.05 & 0.23 & 0.32 & 0.49 & 1.2 \\
Mother $(n=1477)$ & 0.28 & 0.16 & 0.05 & 0.18 & 0.25 & 0.35 & 1.3 \\
Delivery status of mothers & & & & & & & \\
A number of deliveries: 0 $(n=550)$ & 0.32 & 0.17 & 0.05 & 0.21 & 0.28 & 0.39 & 1.3 \\
A number of deliveries: 1 $(n=644)$ & 0.26 & 0.14 & 0.05 & 0.17 & 0.24 & 0.33 & 1.3 \\
A number of deliveries: 2 $(n=234)$ & 0.23 & 0.14 & 0.05 & 0.14 & 0.21 & 0.29 & 0.79 \\
A number of deliveries: 3 $(n=37)$ & 0.22 & 0.15 & 0.05 & 0.12 & 0.19 & 0.25 & 0.71 \\
A number of deliveries: 4 $(n=10)$ & 0.15 & 0.082 & 0.05 & 0.068 & 0.16 & 0.22 & 0.26 \\
A number of deliveries: 5 $(n=2)$ & $<0.1$ & & & & & & \\
\hline
\end{tabular}




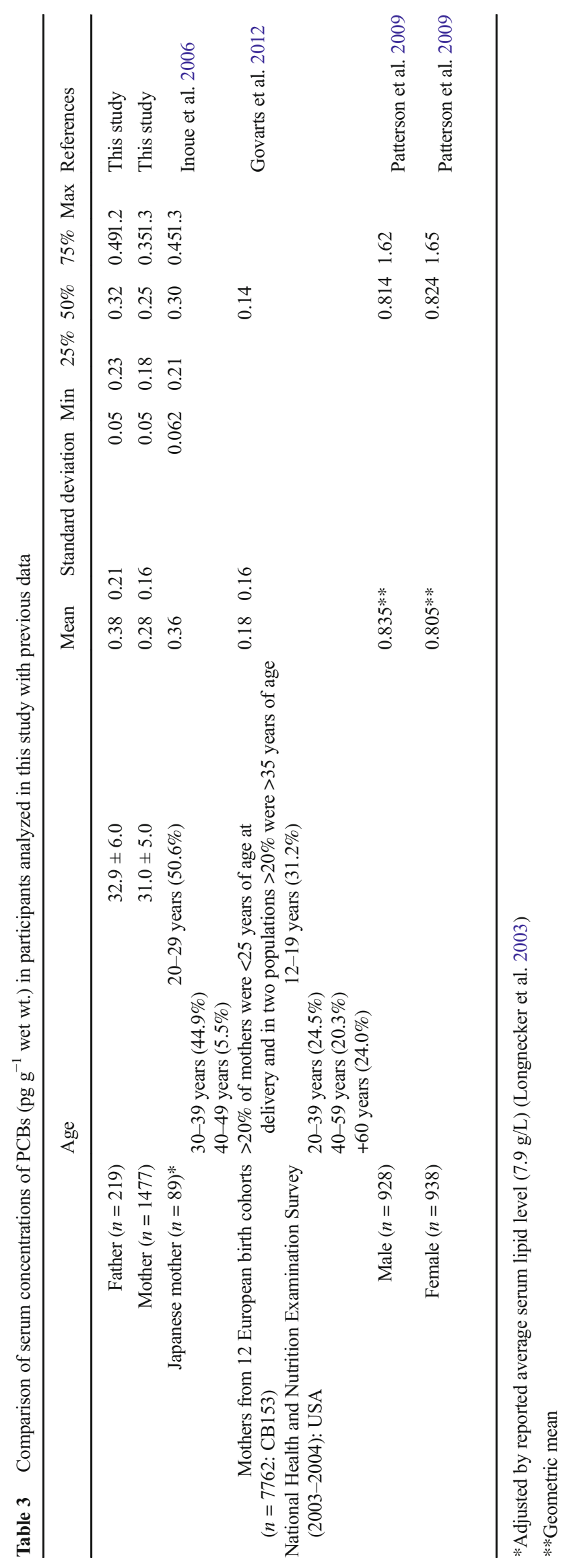


Table 4 Selection of prediction model based on mothers' dataset by WAIC

\begin{tabular}{|c|c|}
\hline & WAIC \\
\hline $\mathrm{PCB} \sim$ age & -1843.5 \\
\hline $\mathrm{PCB} \sim$ age + a number of deliveries & -2012.9 \\
\hline $\mathrm{PCB} \sim$ age + a number of deliveries $+\mathrm{BMI}$ & -2011.4 \\
\hline $\mathrm{PCB} \sim$ age + a number of deliveries + cereals & -2012.2 \\
\hline $\mathrm{PCB} \sim$ age + a number of deliveries + potatoes and starches & -2011.5 \\
\hline $\mathrm{PCB} \sim$ age + a number of deliveries + vegetables & -2013.3 \\
\hline $\mathrm{PCB} \sim$ age + a number of deliveries + fruits & -2011.4 \\
\hline $\mathrm{PCB} \sim$ age + a number of deliveries + fish and shellfish & -2028.5 \\
\hline $\mathrm{PCB} \sim$ age + a number of deliveries + meats & -2011.3 \\
\hline $\mathrm{PCB} \sim$ age + a number of deliveries + eggs & -2014.2 \\
\hline $\mathrm{PCB} \sim$ age + a number of deliveries + milk & -2011.6 \\
\hline $\mathrm{PCB} \sim$ age + a number of deliveries + fats and oils & -2011.5 \\
\hline $\mathrm{PCB} \sim$ age + a number of deliveries + fish and shellfish $+\mathrm{BMI}$ & -2027.5 \\
\hline $\mathrm{PCB} \sim$ age + a number of deliveries + fish and shellfish + cereals & -2027.0 \\
\hline $\mathrm{PCB} \sim$ age + a number of deliveries + fish and shellfish + potatoes and starches & -2027.8 \\
\hline $\mathrm{PCB} \sim$ age + a number of deliveries + fish and shellfish + vegetables & -2027.9 \\
\hline $\mathrm{PCB} \sim$ age + a number of deliveries + fish and shellfish + fruits & -2027.0 \\
\hline PCB $\sim$ age + a number of deliveries + fish and shellfish + meats & -2026.4 \\
\hline$P C B \sim$ age + a number of deliveries + fish and shellfish + eggs & -2030.2 \\
\hline PCB $\sim$ age + a number of deliveries + fish and shellfish + milk & -2028.3 \\
\hline $\mathrm{PCB} \sim$ age + a number of deliveries + fish and shellfish + fats and oils & -2026.7 \\
\hline $\mathrm{PCB} \sim$ age + a number of deliveries + fish and shellfish + eggs + BMI & -2029.2 \\
\hline $\mathrm{PCB} \sim$ age + a number of deliveries + fish and shellfish + eggs + cereals & -2028.4 \\
\hline $\mathrm{PCB} \sim$ age + a number of deliveries + fish and shellfish + eggs + potatoes and starches & -2029.7 \\
\hline PCB $\sim$ age + a number of deliveries + fish and shellfish + eggs + vegetables & -2029.4 \\
\hline $\mathrm{PCB} \sim$ age + a number of deliveries + fish and shellfish + eggs + fruits & -2029.1 \\
\hline $\mathrm{PCB} \sim$ age + a number of deliveries + fish and shellfish + eggs + meats & -2028.3 \\
\hline $\mathrm{PCB} \sim$ age + a number of deliveries + fish and shellfish + eggs + milk & -2030.0 \\
\hline $\mathrm{PCB} \sim$ age + a number of deliveries + fish and shellfish + eggs + fats and oils & -2028.4 \\
\hline
\end{tabular}

*Italicized model was selected with the smallest WAIC positively and a number of deliveries $[\beta=-0.18,95 \% \mathrm{CI}$ $(-0.21,-0.16)]$ was negatively associated with PCB concentrations in mothers (Table 6). However, in our analysis, only age $[\beta=0.25,95 \% \mathrm{CI}(0.19,0.32)]$ was selected for the fathers' model (Tables 5 and 6 ).

The relationship between PCB concentration and age is commonly assumed to result from the continued exposure to or intake of PCB (Mori et al. 2014; Wolff et al. 2007) and the long halflives of PCBs in the human body (Ritter et al. 2011). In a former study, our group also reported that delivery experience and lactation affected the PCB concentration level in adults (Mori et al. 2014), indicating women may excrete PCBs through delivery and lactation (Agudo et al. 2009; Kang et al. 1997).

Studies have demonstrated that the dietary intake of fish is a major pathway for human exposure to PCBs (Caspersen et al. 2013; Kvalem et al. 2009; Sjodin et al. 2000). Fitzgerald et al. (2004) reported that Mohawk women had high serum levels of PCBs that were associated with consumption of local fish and not with the exposure to other sources, like residential soil, lived sites, and the other foodstuff (Fitzgerald et al. 2004). Furthermore, it was reported that fish and shellfish accounted for $30-84 \%$ of the dioxin toxic equivalences from food intake by a Japanese total-diet study (Sasamoto et al. 2006), indicating that dioxin and dioxin-like PCB intake also occurs through fish and shellfish. Sasamoto et al. (2006) reported that meat and egg consumption comprised the second highest contribution to dietary intake of dioxins and dioxin-like PCBs, indicating that egg consumption may be associated with higher serum dioxin and dioxinlike PCB concentrations. The Bureau of Social Welfare and Public Health, Tokyo Metropolitan Government, showed the levels of PCBs in meat and eggs were below the detection limit in a food contamination survey (Bureau of Social Welfare and Public Health, Tokyo Metropolitan Government, 2015); however, continuous monitoring of PCBs in these foodstuffs might be needed.

In mother's models, effect sizes of food intakes were 1 order lower than that of age and delivery experience, 
Table 5 Selection of prediction model based on fathers' dataset by WAIC

\begin{tabular}{lc}
\hline & WAIC \\
\hline PCB $\sim$ age & -172.8 \\
PCB $\sim$ age + BMI & -172.4 \\
PCB $\sim$ age + cereals & -171.0 \\
PCB $\sim$ age + potatoes and starches & -172.5 \\
PCB $\sim$ age + vegetables & -169.9 \\
PCB $\sim$ age + fruits & -171.9 \\
PCB $\sim$ age + fish and shellfish & -172.0 \\
PCB $\sim$ age + meats & -170.9 \\
PCB $\sim$ age + eggs & -171.4 \\
PCB $\sim$ age + milks & -171.7 \\
PCB $\sim$ age + fats and oils & -170.7 \\
PCB $\sim$ age + potatoes and starches + BMI & -172.2 \\
PCB $\sim$ age + potatoes and starches + cereals & -171.2 \\
PCB $\sim$ age + potatoes and starches + vegetables & -170.0 \\
PCB $\sim$ age + potatoes and starches + fruits & -171.0 \\
PCB $\sim$ age + potatoes and starches + meats & -171.1 \\
PCB $\sim$ age + potatoes and starches + fish and shellfish & -171.0 \\
PCB $\sim$ age + potatoes and starches + eggs & -171.3 \\
PCB $\sim$ age + potatoes and starches + milk & -171.4 \\
PCB $\sim$ age + potatoes and starches + fats and oils & -171.2 \\
\hline &
\end{tabular}

*Italicized model was selected with the smallest WAIC

indicating the effect of food intake on serum PCB concentrations was weaker than that of age and number of deliveries. However, fish intake was included in the final model in mothers, indicating FFQ might be useful to estimate the PCB levels. In the father's model, only age is predictive of serum PCB concentrations. Due to lack of information about smoking habits and limitation of sample size of father, development of improved predictive models and detailed investigations are required in future study.
Limitations of this study were lack of data about breastfeeding and smoking habit. Several studies have reported that breast-feeding is one of the major elimination pathways of persistent organic pollutants (POPs) (Abraham et al. 1996; Milbrath et al. 2009; Schecter et al. 1996), and after 6 months of breast-feeding, approximately $20 \%$ or more of the maternal body burden of these POPs may be transferred to children from mothers (Landrigan et al. 2002; Milbrath et al. 2009; Niessen et al. 1984). These results indicated that the number of deliveries is most likely a surrogate for breast-feeding. It was also reported that the active smoking was negatively affected to levels of PCB and dioxin in serum (Chen et al. 2005; Milbrath et al. 2009) through increased induction of dioxindegrading enzymes, like cytochrome $\mathrm{P} 450$, by activation of the aryl hydrocarbon receptor by polycyclic aromatic hydrocarbons in tobacco smoke (Milbrath et al. 2009; Zevin and Benowitz 1999). Thus, information about smoking status and breast-feeding will be needed to develop more accurate predictive models in any future study.

\section{Conclusion}

In the current study, we developed a preliminary model to estimate the serum PCB levels from FFQ and other demographic/reproductive data collected from medical records. Finally, in mothers, age and consumption of fish and eggs were positively associated and the number of deliveries was negatively associated with PCB concentration. On the other hand, only age was positively associated with PCBs in fathers in this study.

In previous studies, it was shown that age was strongly related to exposure of PCBs, due to intake of PCB and long half-lives of PCBs in the human body. On the other hand, only women might excrete the PCBs through delivery and lactation. Dietary exposure to PCBs, especially in
Table 6 Empirical mean (mean), standard deviation of the mean (SD), and quantiles for each variable in selected prediction model for mothers and fathers

\begin{tabular}{|c|c|c|c|c|c|c|c|c|}
\hline & \multicolumn{4}{|l|}{ Mothers } & \multicolumn{4}{|l|}{ Fathers } \\
\hline & Coefficient & $\begin{array}{l}\text { Standard } \\
\text { deviation }\end{array}$ & $\begin{array}{l}95 \% \\
\text { lower }\end{array}$ & $\begin{array}{l}95 \% \\
\text { upper }\end{array}$ & Coefficient & $\begin{array}{l}\text { Standard } \\
\text { deviation }\end{array}$ & $\begin{array}{l}95 \% \\
\text { lower }\end{array}$ & $\begin{array}{l}95 \% \\
\text { upper }\end{array}$ \\
\hline Intercept & -1.32 & 0.013 & -1.34 & -1.29 & -1.0 & 0.032 & -1.1 & -0.93 \\
\hline Age & 0.26 & 0.014 & 0.23 & 0.29 & 0.25 & 0.033 & 0.19 & 0.32 \\
\hline $\begin{array}{l}\text { A number } \\
\text { of } \\
\text { deliveries }\end{array}$ & -0.18 & 0.013 & -0.21 & -0.16 & NA & & & \\
\hline $\begin{array}{l}\text { Fish and } \\
\text { shellfish }\end{array}$ & 0.055 & 0.013 & 0.029 & 0.082 & Omitted & & & \\
\hline Eggs & 0.025 & 0.013 & -0.00027 & 0.052 & Omitted & & & \\
\hline
\end{tabular}

"Omitted" indicates factors eliminated by stepwise procedures

NA not analyzed 
relation to fish consumption, was also reported, indicating out results that supported the previous cohort studies, even in the current Japanese cohort study. While the limitations about the smoking habits and breast-feeding existed, this study shows that the FFQ may help predict PCB levels in serum from women. In the future, development of the more accurate predictive models using information about the smoking status and breast-feeding was needed.

Acknowledgments These studies were supported by grants for scientific research (A): grants-in-aid for scientific research KAKENHI (20241016) and scientific research (B): grants-in-aid for scientific research KAKENHI (24310021) from the Japanese Ministry of Education Culture, Sports, Science and Technology, Global Environment Research Fund (C-0904), A Waste Management Research Grant (K2121), and the Environment Research and Technology Development Fund (5-1305) from the Ministry of the Environment of Japan. This study was conducted as an adjunct study of JECS. The findings and conclusions of this article are solely the responsibility of the authors and do not represent the official views of the above government.

Open Access This article is distributed under the terms of the Creative Commons Attribution 4.0 International License (http:// creativecommons.org/licenses/by/4.0/), which permits unrestricted use, distribution, and reproduction in any medium, provided you give appropriate credit to the original author(s) and the source, provide a link to the Creative Commons license, and indicate if changes were made.

\section{References}

Abraham K, Knoll A, Ende M, Papke O, Helge H (1996) Intake, fecal excretion, and body burden of polychlorinated dibenzo-p-dioxins and dibenzofurans in breast-fed and formula-fed infants. Pediatr Res 40:671-679

Agudo A et al (2009) Polychlorinated biphenyls in Spanish adults: determinants of serum concentrations. Environ Res 109:620-628

Ayotte P, Muckle G, Jacobson JL, Jacobson SW, Dewailly E, Inuit Cohort S (2003) Assessment of pre- and postnatal exposure to polychlorinated biphenyls: lessons from the Inuit cohort study. Environ Health Perspect 111:1253-1258

Bureau of Social Welfare and Public Health, Tokyo Metropolitan Government (2015) Food contamination survey of PCBs. http://www.fukushihoken.metro.tokyo.jp/shokuhin/osen/files/2014 pcb.pdf. Accessed 09222016

Caspersen IH, Knutsen HK, Brantsaeter AL, Haugen M, Alexander J, Meltzer HM, Kvalem HE (2013) Dietary exposure to dioxins and PCBs in a large cohort of pregnant women: results from the Norwegian mother and child cohort study (MoBa). Environ Int 59: 398-407

Chen HL, Liao PC, Su HJ, Guo YL, Chen CH, Lee CC (2005) Profile of $\mathrm{PCDD} / \mathrm{F}$ levels in serum of general Taiwanese between different gender, age and smoking status. Sci Total Environ 337:31-43

Drewnowski A, Specter SE (2004) Poverty and obesity: the role of energy density and energy costs. Am J Clin Nutr 79:6-16

Fitzgerald EF et al (2004) Fish consumption and other environmental exposures and their associations with serum PCB concentrations among Mohawk women at Akwesasne. Environ Res 94:160-170

Gelman A, Carlin JB, Stern HS, Rubin DB (2014) Bayesian data analysis vol 2. Taylor \& Francis,
Glynn A, Thuvander A, Aune M, Johannisson A, Darnerud PO, Ronquist $\mathrm{G}$, Cnattingius S (2008) Immune cell counts and risks of respiratory infections among infants exposed pre- and postnatally to organochlorine compounds: a prospective study. Environ Health 7:62

Govarts E et al (2012) Birth weight and prenatal exposure to polychlorinated biphenyls (PCBs) and dichlorodiphenyldichloroethylene (DDE): a meta-analysis within 12 European birth cohorts. Environ Health Perspect 120:162-170

Hoffman MD, Gelman A (2014) The No-U-Turn Sampler: adaptively setting path lengths in Hamiltonian Monte Carlo. J Mach Learn Res 15:1593-1623

Inoue $\mathrm{K}$ et al (2006) Levels and concentration ratios of polychlorinated biphenyls and polybrominated diphenyl ethers in serum and breast milk in Japanese mothers. Environ Health Perspect 114:1179-1185

Ishihara J et al (2003) Validity and reproducibility of a self-administered food frequency questionnaire in the JPHC study cohort II: study design, participant profile and results in comparison with cohort I. Journal of epidemiology / Japan Epidemiological Association 13: S134-S147

Iso $\mathrm{H}$, Moriyama Y, Yoshino $\mathrm{K}$, Sasaki S, Ishihara J, Tsugane S, JPHC (2003) Validity of the self-administered food frequency questionnaire used in the 5-year follow-up survey for the JPHC study to assess folate, vitamin B6 and B12 intake: comparison with dietary records and blood level. Journal of epidemiology / Japan Epidemiological Association 13:S98-101

James RA, Hertz-Picciotto I, Willman E, Keller JA, Charles MJ (2002) Determinants of serum polychlorinated biphenyls and organochlorine pesticides measured in women from the child health and development study cohort, 1963-1967. Environ Health Perspect 110:617624

JIS K 0093: 2006. Testing methods for polychlorobiphenyl in industrial water and wastewater (in Japanese) .

Jorissen J (2007) Literature review. Outcomes associated with postnatal exposure to polychlorinated biphenyls (PCBs) via breast milk. Adv Neonatal Care 7:230-237

Jotaki T, Fukata H, Mori C (2011) Confirmation of polychlorinated biphenyl (PCB) distribution in the blood and verification of simple quantitative method for PCBs based on specific congeners. Chemosphere 82:107-113

Kawamoto T et al (2014) Rationale and study design of the Japan environment and children's study (JECS). BMC Public Health 14:25. doi: 10.1186/1471-2458-14-25

Kvalem HE et al (2009) Role of dietary patterns for dioxin and PCB exposure. Mol Nutr Food Res 53:1438-1451

Laden F et al (1999) Predictors of plasma concentrations of DDE and PCBs in a group of U.S. women. Environ Health Perspect 107:75-81

Landrigan PJ, Sonawane B, Mattison D, McCally M, Garg A (2002) Chemical contaminants in breast milk and their impacts on children's health: an overview. Environ Health Perspect 110:A313-A315

Leoni V et al (1989) PCB and other organochlorine compounds in blood of women with or without miscarriage: a hypothesis of correlation. Ecotoxicol Environ Saf 17:1-11

Longnecker MP et al (2003) Comparison of polychlorinated biphenyl levels across studies of human neurodevelopment. Environ Health Perspect 111:65-70

Milbrath MO, Wenger Y, Chang CW, Emond C, Garabrant D, Gillespie BW, Jolliet O (2009) Apparent half-lives of dioxins, furans, and polychlorinated biphenyls as a function of age, body fat, smoking status, and breast-feeding. Environ Health Perspect 117:417-425. doi:10.1289/ehp.11781

Mori C et al (2014) Polychlorinated biphenyl levels in the blood of Japanese individuals ranging from infants to over 80 years of age. Environ Sci Pollut R 21:6434-6439

Niessen KH, Ramolla J, Binder M, Brugmann G, Hofmann U (1984) Chlorinated hydrocarbons in adipose tissue of infants and toddlers: 
inventory and studies on their association with intake of mothers' milk. Eur J Pediatr 142:238-244

Patterson DG Jr et al (2009) Levels in the U.S. population of those persistent organic pollutants (2003-2004) included in the Stockholm convention or in other long range transboundary air pollution agreements. Environ Sci Technol 43:1211-1218

Prince MM et al (2006) Mortality and exposure response among 14,458 electrical capacitor manufacturing workers exposed to polychlorinated biphenyls (PCBs). Environ Health Perspect 114: $1508-1514$

R Core Team. 2014 R: A language and environment for statistical computing. R Foundation for Statistical Computing, Vienna

Ritter R, Scheringer M, MacLeod M, Moeckel C, Jones KC, Hungerbuhler K (2011) Intrinsic human elimination half-lives of polychlorinated biphenyls derived from the temporal evolution of cross-sectional biomonitoring data from the United Kingdom. Environ Health Perspect 119:225-231

Safe SH (1994) Polychlorinated biphenyls (PCBs): environmental impact, biochemical and toxic responses, and implications for risk assessment. Crit Rev Toxicol 24:87-149

Sakurai K, Todaka E, Saito Y, Mori C (2004) Pilot study to reduce dioxins in the human body. Intern Med 43:792-795

Sasaki S, Kobayashi M, Ishihara J, Tsugane S (2003) Self-administered food frequency questionnaire used in the 5-year follow-up survey of the JPHC study: questionnaire structure, computation algorithms, and area-based mean intake. Journal of Epidemiology 13:S13-S22

Sasamoto T et al (2006) Estimation of 1999-2004 dietary daily intake of PCDDs, PCDFs and dioxin-like PCBs by a total diet study in metropolitan Tokyo, Japan. Chemosphere 64:634-641

Schecter A et al (1996) Decrease in milk and blood dioxin levels over two years in a mother nursing twins: estimates of decreased maternal and increased infant dioxin body burden from nursing. Chemosphere 32: 543-549

Sjodin A, Hagmar L, Klasson-Wehler E, Bjork J, Bergman A (2000) Influence of the consumption of fatty Baltic Sea fish on plasma levels of halogenated environmental contaminants in Latvian and Swedish men. Environ Health Perspect 108:1035-1041

Stan development Team (2015): the R interface to Stan, Version 2.8.0. http://mc-stan.org/rstan.html

Takasuga T, Senthilkumar K, Takemori H, Ohi E, Tsuji H, Nagayama J (2004) Impact of fermented brown rice with Aspergillus oryzae
(FEBRA) intake and concentrations of polybrominated diphenylethers (PBDEs) in blood of humans from Japan. Chemosphere 57:795-811

Tsubono Y, Kobayashi M, Sasaki S, Tsugane S, JPHC (2003) Validity and reproducibility of a self-administered food frequency questionnaire used in the baseline survey of the JPHC study cohort I. Journal of epidemiology / Japan Epidemiological Association 13:S125-S133

Tsugane S, Kobayashi M, Sasaki S (2003a) Validity of the self-administered food frequency questionnaire used in the 5-year follow-up survey of the JPHC study cohort I: comparison with dietary records for main nutrients. Journal of Epidemiology 13:S51-S56

Tsugane S, Sasaki S, Kobayashi M, Tsubono Y, Akabane M, JPHC (2003b) Validity and reproducibility of the self-administered food frequency questionnaire in the JPHC study cohort I: study design, conduct and participant profiles. Journal of epidemiology / Japan Epidemiological Association 13:S2-12

Tsukino $\mathrm{H}$ et al (2006) Fish intake and serum levels of organochlorines among Japanese women. Sci Total Environ 359:90-100

UNEP (2001) Final act of the conference of Plenipotentaries on the Stockholm convention on persistent organic pollutant. Stockholm, Sweden

Vehtari A, Gelman A (2014) WAIC and cross-validation in Stan. Submitted. http://www.stat. columbia.edu/ gelman/research/unpublished/waic_stan.pdf Accessed 09222016

Watanabe S (2010) Asymptotic equivalence of Bayes cross validation and widely applicable information criterion in singular learning theory. J Mach Learn Res 11:3571-3594

Willett WC (1994) Future-directions in the development of foodfrequency questionnaires. Am J Clin Nutr 59:171s-174s

Wolff MS, Anderson HA, Britton JA, Rothman N (2007) Pharmacokinetic variability and modern epidemiology - the example of dichlorodiphenyltrichloroethane, body mass index, and birth cohort. Cancer Epidem Biomar 16:1925-1930

Xue J, Liu SV, Zartarian VG, Geller AM, Schultz BD (2014) Analysis of NHANES measured blood PCBs in the general US population and application of SHEDS model to identify key exposure factors. J Expo Sci Environ Epidemiol 24:615-621

Zevin S, Benowitz NL (1999) Drug interactions with tobacco smoking. An update Clinical pharmacokinetics 36:425-438 